\title{
Advice to use topical or oral ibuprofen for chronic knee pain in older people: randomised controlled trial and patient preference study
}

\author{
Martin Underwood, professor of general practice, ${ }^{1}$ Deborah Ashby, professor of medical statistics, ${ }^{2}$ \\ Pamela Cross, study clinician, ${ }^{1}$ Enid Hennessy, senior lecturer in medical statistics, ${ }^{2}$ Louise Letley, senior \\ nurse manager , ${ }^{3}$ Jeannett Martin, visiting fellow, ${ }^{4}$ Shahrul Mt-Isa, statistician , ${ }^{2}$ Suzanne \\ Parsons, research fellow, ${ }^{1}$ Madge Vickers, research director ${ }^{5}$ Ken Whyte, study manager ${ }^{1}$, on behalf of \\ the TOIB study team
}

\begin{abstract}
${ }^{1}$ Centre for Health Sciences, Barts and The London, Queen Mary, University of London, London

E1 2AT

${ }^{2}$ Wolfson Institute of Preventive Medicine, Barts and The London, Queen Mary, University of London, London EC1M 6BQ

${ }^{3}$ MRC General Practice Research Framework, London NW1 2ND

${ }^{4}$ Department of Primary and Social Care, London South Bank University, London SE1 6EN

${ }^{5}$ Clinical Trials Co-ordinating Centre, University of

Hertfordshire, Hatfield, Herts AL10 9LB

Correspondence to: $M$ Underwood m.underwood@qmul.ac.uk
\end{abstract}

doi:10.1136/bmj.39399.656331.25

\section{ABSTRACT}

Objective To determine whether older patients with chronic knee pain should be advised to use topical or oral non-steroidal anti-inflammatory drugs (NSAIDs).

Design Randomised controlled trial and patient preference study.

Setting 26 general practices.

Participants People aged $\geq 50$ with knee pain: 282 in randomised trial and 303 in preference study. Interventions Advice to use topical or oral ibuprofen. Primary outcome measures WOMAC (Western Ontario and McMaster Universities) osteoarthritis index, major and minor adverse effects.

Results Changes in global WOMAC scores at 12 months were equivalent. In the randomised trial the difference (topical minus oral) was two points (95\% confidence interval -2 to 6$)$; in the preference study, it was one point ( -4 to 6). There were no differences in major adverse effects in the trial or study. The only significant differences in secondary outcomes were in the randomised trial. The oral group had more respiratory adverse effects $(17 \% \mathrm{~V}$ $7 \%, 95 \%$ confidence interval for difference $-17 \%$ to $-2 \%$ ), the change in serum creatinine was $3.7 \mathrm{mmol} / \mathrm{l}$ less favourable $(0.9 \mu \mathrm{mol} / \mathrm{l}$ to $6.5 \mu \mathrm{mol} / \mathrm{l})$; and more participants changed treatments because of adverse effects $(16 \% v 1 \%,-16 \%$ to $-5 \%)$. In the topical group more participants had chronic pain grade III or IV at three months, and more participants changed treatment because of ineffectiveness.

Conclusions Advice to use oral or topical preparations has an equivalent effect on knee pain over one year, and there are more minor side effects with oral NSAIDs. Topical NSAIDs may be a useful alternative to oral NSAIDs. Trial registration ISRCTN 79353052.

\section{INTRODUCTION}

Around a third of people aged over 50 years have chronic knee pain. ${ }^{1-4}$ Both oral and topical nonsteroidal anti-inflammatory drugs (NSAIDs) are used to treat this and both have some short term beneficial effects. $^{5-9}$ If topical NSAIDs are as effective as oral NSAIDs for reducing knee pain but produce fewer adverse effects, then topical treatment might be preferred. As the route of administration is different, non-pharmacological factors may affect the response to treatment. Thus, patients' preferences for topical or oral treatment might have an important effect on perceived benefit and the incidence of subjective adverse effects and should be considered in the recommended route of administration. These preferences need to be considered in any pragmatic study comparing topical or oral administration. The popularity of comparatively expensive topical NSAIDs and the importance of adverse effects related to NSAIDs meant that the NHS Health Technology Assessment programme identified a comparison of oral and topical NSAIDs for osteoarthritis as a priority for research.

Here we compare the effect of advice to use oral or topical NSAIDs on knee pain and disability, minor adverse effects related to use of NSAIDs, overall pain, and health related quality of life.

\section{METHOD}

We have described our methods in detail elsewhere. ${ }^{10}$

\section{Recruitment}

We recruited general practices from the Medical Research Council general practice research framework (GPRF) ${ }^{11}$ We sent postal invitations to patients who had consulted these practices with osteoarthritis or knee or leg pain in the preceding five years or who had had a prescription for a topical or an oral NSAID or a rubefacient over the preceding year. Research nurses based in the practices then confirmed whether potential participants met our eligibility and safety criteria and took blood samples for baseline laboratory tests (boxes 1 and 2). To be included participants had to be aged $\geq 50$, have had troublesome pain in or around the knee on most days for at least a month as well as knee pain for more than three months in the preceding 
Box 1 Criteria for exclusion on grounds of safety

- Peptic ulceration (past or current)

- Indigestion on most days in past three months

- Previous adverse reaction to NSAIDs

- Raised blood pressure $\geq 155 / 95 \mathrm{~mm} \mathrm{Hg}$ (mean of three readings at study entry)

- Uncontrolled heart failure

- Serum creatinine concentration $>140 \mu \mathrm{mol} / \mathrm{l}$

- Abnormal liver function sufficient to contraindicate use of NSAIDs

- Taking anticoagulants or oral steroids

- Haemoglobin $<124 \mathrm{~g} / \mathrm{l}$ for men or $<118 \mathrm{~g} / \mathrm{l}$ for women

- Disseminated malignancy

- Request by general practitioner not to include potential participant for any other reason

year; have consulted or been prescribed treatment by the general practitioner for knee pain in the preceding three years; have no current or planned knee replacements; and meet our safety criteria (box 1$){ }^{412}$ Each participant was assessed by a general practitioner who confirmed they were willing to prescribe NSAIDs for this participant and recorded the physical components of the American College of Rheumatologists' clinical criteria for knee osteoarthritis. ${ }^{13}$ At a subsequent assessment at study entry the research nurses confirmed eligibility, obtained informed consent, and collected baseline data (box 1 and table 1). Potential participants were asked not to use any topical or oral NSAIDs for one week before the assessment at study entry. Participants were offered a choice of joining the randomised trial or the preference study. Participants in the randomised study were then randomised and those who joined the preference study selected their treatment. We provided participants with a starter pack of their chosen or allocated treatment. After this participants were either prescribed medication by the practice or they could purchase their own over the counter.

\section{Quality control}

All the research nurses had a full day of training in the study procedures and were visited at least once during the study by a regional training nurse or a senior research nurse from the general practice research framework to ensure that the protocol was being followed.

\section{Assignment}

We used a remote computer based telephone randomisation service to register participants and to allocate participants in the randomised study to treatment groups. Randomisation was stratified by practice and troublesomeness of knee pain. ${ }^{14}$

\section{Participant flow and follow-up}

We followed up participants with postal questionnaires at $3,6,12$, and 24 months after study entry, with two reminders. There were nurse assessments and blood tests at 12 and 24 months. Because recruitment was slow, not all participants could be followed for 24 months; participants with 16-24 months of followup at the end of data collection underwent 24 month (end of study) assessments at this time; for those with 12-16 months of potential follow-up we did the end of study assessments after 12 months. We collected data on health service activity and prescribing from randomisation to 24 months or end of study.

\section{Intervention}

In the randomised trial we compared a recommendation to use either a topical or an oral NSAID, preferably ibuprofen, as required for knee pain. In the preference study the recommendation was to use the route of delivery preferred by the patient. The medication could be either prescribed or bought over the counter. If a change of medication was required, participants were encouraged, when appropriate, to use an alternative NSAID with the same route of administration.

\section{Masking}

The study was not blinded at the general practice or participant level. All other members of the study team involved in data collection were blind to the participants' chosen or allocated treatment.

\section{Outcome measures}

For our primary efficacy analyses we used follow-up questionnaires at 12 months. Our primary efficacy outcome measure was the WOMAC (Western Ontario and McMaster Universities) VA 3.1 questionnaire,

\section{Box 2 Criteria for minor adverse effects*}

\section{Gastrointestinal}

- Haemoglobin concentration $<113 \mathrm{~g} / \mathrm{l}$ (male)*

- Haemoglobin concentration $<106 \mathrm{~g} / \mathrm{l}$ (female)*

- Fall in haemoglobin concentration $\geq 16 \mathrm{~g} / \mathrm{l}$

- Ferritin concentration below lower limit of normal

- Indigestion more than occasionally

- Increase in indigestion by $\geq$ one category

Renovascular

- Creatinine concentration $\geq 152 \mu \mathrm{mol} / \mathrm{l}^{*}$

- Increase in creatinine concentration $\geq 20 \mu \mathrm{mol} /$ l* $^{\star}$

- Increase in systolic blood pressure $\geq 20 \mathrm{~mm} \mathrm{Hg}$

- Increase in diastolic blood pressure $\geq 10 \mathrm{~mm} \mathrm{Hg}$

- New diagnosis of heart failure

Respiratory

- New diagnosis of asthma or COPD

- New treatment for asthma or COPD

- $\geq 15 \%$ fall in peak flow

* This includes tests done as part of routine care within 18 months of randomisation, but excludes those done after one year nurse assessment had been completed.

†Categories: no days; few days (occasionally); more than occasionally, but fewer than half the days; most days (half or more of the days); every day. 
which measures knee pain and disability in the preceding 48 hours and produces individual measures of pain, stiffness, and physical function and a global assessment. $^{15}$ For our secondary efficacy outcome measures we used the postal version of the chronic pain grade, which measures overall pain and disability related to pain over the preceding six months, ${ }^{1617}$ and the SF-36v2, a well established measure of health related quality of life over the preceding four weeks, reported as physical and mental component scores. ${ }^{1819}$

\section{Adverse effects}

We defined a major adverse effect as an unplanned hospital admission or death during follow-up. We identified deaths from practice records and from flagging participants at the NHS central registry. Practices provided copies of participants' hospital discharge letters during the study period. Two members of the study team (MU, PC) who were blind to allocation independently coded these as planned or unplanned admissions, conferring only to resolve any disagreements.

We defined a minor adverse effect as a change in one or more selected variables that a Delphi panel of general practitioners considered serious enough to entail advising a change of treatment (box2). ${ }^{20} \mathrm{We}$ also report the differences in clinical and laboratory study measures, participants' reports of changing treatment because of adverse effects, and, when appropriate, the results of laboratory tests initiated by the practice. We used questionnaire data at 3,6 , and 12 months, results of blood tests taken up to and including those taken at the 12 month nurse assessment (so long as these were collected within 18 months), and medical record data up to 12 months.

\section{Prescribing data}

We calculated the number of defined daily doses of oral ibuprofen, other oral NSAIDs, rescue analgesia (paracetamol or opioids), treatments for dyspepsia, and respiratory and cardiovascular drugs (except aspirin) prescribed with standardised values. ${ }^{21}$ For oral ibuprofen the defined daily dose is $1.2 \mathrm{~g}$. For topical NSAIDs and rubefacients we defined a daily dose for one knee as $1.5 \mathrm{~g} .{ }^{20}$ All analyses on prescribing data are based on prescriptions issued in the first year after participants joined the study.

\section{Sample size}

Our hypothesis was that there would be equivalence in means between groups for the WOMAC score. Typically, standard deviations for the WOMAC in knee osteoarthritis trials are around $22 \mathrm{~mm}$. We defined equivalence as $95 \%$ confidence that the difference between groups lay within $10 \mathrm{~mm}$. To show this with $80 \%$ power and $5 \%$ significance, assuming $25 \%$ loss to follow-up, we needed 275 participants in the randomised trial. Early recruitment data indicated a 3:1 preference for topical compared with oral treatment in the preference study and a $2: 1$ preference for joining the preference study, which compromised the original sample size calculations. ${ }^{10}$ To ensure recruitment to the randomised trial the last seven practices to join the study recruited only to the randomised trial. Allowing for the unequal group size, we needed 368 participants in the preference study.

\section{Analysis}

We analysed the two studies separately. When appropriate we adjusted for baseline values using regression models. For other analyses we used $t$ tests, differences

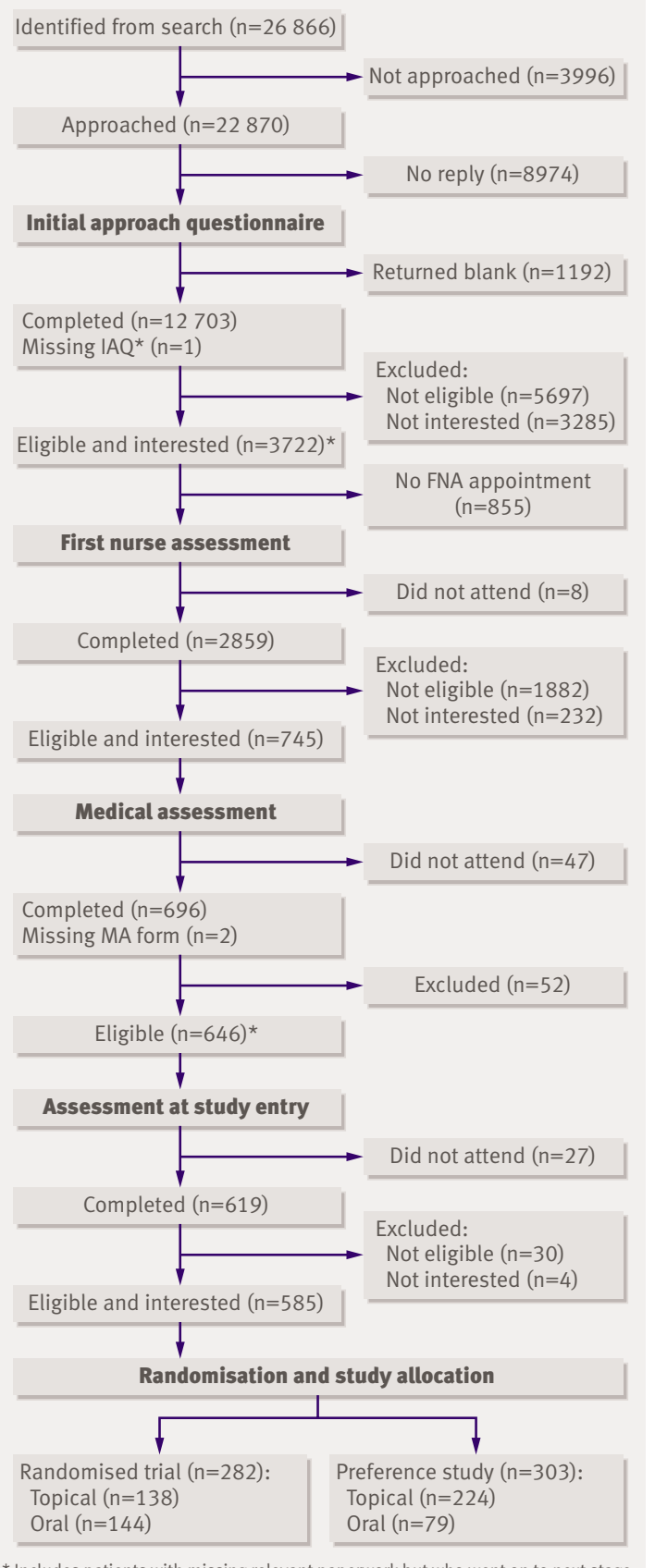

* Includes patients with missing relevant paperwork but who went on to next stage.

Fig 1 Flow chart of recruitment to both studies 
Table 1 | Baseline characteristics of participants in randomised trial and preference study according to treatment with oral or topic NSAIDs for knee pain. Figures are means (SDs) unless stated otherwise

\begin{tabular}{|c|c|c|c|c|}
\hline & \multicolumn{2}{|c|}{ Randomised trial } & \multicolumn{2}{|c|}{ Preference study } \\
\hline & Oral & Topical & Oral & Topical \\
\hline No of participants & 144 & 138 & 79 & 224 \\
\hline \multicolumn{5}{|l|}{ Demographic data } \\
\hline No (\%) of men & $63(44)$ & $68(49)$ & $31(39)$ & $95(42)$ \\
\hline Mean age at randomisation (median, IQR) & $63(60,56-69)$ & $63(60,56-68)$ & $64(64,57-72)$ & $66(66,60-72)$ \\
\hline No (\%) with occupational codes $1-3^{30 *}$ & $54(38)$ & $39(28)$ & $24(30)$ & $53(24)$ \\
\hline No (\%) who met clinical criteria for osteoarthritis ${ }^{13}$ & 140 (98) & $134(97)$ & $79(100)$ & $217(97)$ \\
\hline Mean BMI (median, IQR) & $31(29,26-34)$ & $30(29,26-32)$ & $30(29,27-33)$ & $29(28,26-32)$ \\
\hline \multicolumn{5}{|l|}{ Pain/wellbeing } \\
\hline \multicolumn{5}{|l|}{ WOMAC (each scale range $0-100 \dagger$ ): } \\
\hline No of participants with data & 144 & 135 & 76 & 216 \\
\hline Pain score & $39(21.5)$ & 39 (19.3) & $39(19.3)$ & $41(20.1)$ \\
\hline Stiffness & $47(25.7)$ & $50(24.6)$ & $50(22.4)$ & $49(24.9)$ \\
\hline Difficulty & $38(23.1)$ & $37(18.3)$ & $41(20.2)$ & $40(20.4)$ \\
\hline Global & $39(22.0)$ & $38(17.6)$ & $41(18.7)$ & $41(19.4)$ \\
\hline \multicolumn{5}{|l|}{ EQ-5D utility score: } \\
\hline No of participants with data & 140 & 138 & 78 & 219 \\
\hline Score & $0.65(0.22)$ & $0.67(0.19)$ & $0.63(0.23)$ & $0.66(0.19)$ \\
\hline \multicolumn{5}{|l|}{ Chronic pain grade: } \\
\hline No of participants with data & 141 & 136 & 78 & 219 \\
\hline Pain intensity & $52.6(19.9)$ & $52.0(18.2)$ & $54.9(18.3)$ & $51.9(18.4)$ \\
\hline Disability & $38.5(27.3)$ & $34.5(23.4)$ & $37.6(23.3)$ & $35.3(25.7)$ \\
\hline No (\%) with grade III or IV & $50(35)$ & $35(26)$ & $26(33)$ & $68(31)$ \\
\hline \multicolumn{5}{|l|}{ SF-36 (SD): } \\
\hline No of participants with data & 138 & 136 & 74 & 209 \\
\hline Physical component score & $39.0(9.7)$ & $39.2(8.9)$ & $37.7(7.8)$ & $38.5(9.4)$ \\
\hline Mental component score & $52.0(10.2)$ & $53.7(9.6)$ & $51.7(10.4)$ & $52.0(10.0)$ \\
\hline No (\%) with very/extremely troublesome knee pain ${ }^{14}$ & 45/144 (31) & 45/138 (33) & $26 / 79(33)$ & $66 / 224(29)$ \\
\hline \multicolumn{5}{|l|}{ No (\%) with indigestion in past 3 months: } \\
\hline No of participants with data & 144 & 138 & 78 & $224 \ddagger$ \\
\hline None & $86(60)$ & $78(57)$ & $47(59)$ & $106(47)$ \\
\hline A few days or occasionally & $50(35)$ & $54(39)$ & $28(35)$ & $106(47)$ \\
\hline Over occasional-less than $50 \%$ of time & $8(6)$ & $6(4)$ & $3(4)$ & $11(5)$ \\
\hline \multicolumn{5}{|l|}{ No (\%) who used NSAIDs in past year: } \\
\hline No of participants with data & 141 & 138 & 78 & 223 \\
\hline Used neither oral nor topical & $34(24)$ & $20(14)$ & $8(10)$ & $64(29)$ \\
\hline Used oral only & $59(41)$ & $81(59)$ & $49(62)$ & $82(37)$ \\
\hline Used topical only & $9(6)$ & $8(6)$ & $1(1)$ & $40(18)$ \\
\hline Used both topical and oral & $39(27)$ & $28(20)$ & $21(27)$ & $37(17)$ \\
\hline \multicolumn{5}{|l|}{ No (\%) with other pain: } \\
\hline No of participants with data & 143 & 138 & 79 & 221 \\
\hline $\begin{array}{l}\text { At least one more area of at least moderately } \\
\text { troublesome pain } \\
\end{array}$ & $101(71)$ & $97(71)$ & $66(84) \S$ & $160(73) \S$ \\
\hline \multicolumn{5}{|l|}{ Expectation (\%): } \\
\hline $\begin{array}{l}\text { How helpful do you think tablets will be? (very, } \\
\text { helpful, not helpful) }\end{array}$ & $30,63,7(n=144)$ & $28,64,8(n=136)$ & $44,54,1(n=79)$ & $11,59,30(n=222)$ \\
\hline $\begin{array}{l}\text { How helpful do you think ointment will be? (very, } \\
\text { helpful, not helpful) }\end{array}$ & $30,59,10(n=138)$ & $16,67,17(n=135)$ & $7,48,45(n=71)$ & $30,69,1(n=216)$ \\
\hline \multicolumn{5}{|c|}{ Blood pressure (average of three readings before study entry?) } \\
\hline No of participants with data & 142 & 138 & 76 & 222 \\
\hline Systolic $(\mathrm{mm} \mathrm{Hg})$ & $134(15)$ & $131(15)$ & $135(15)$ & $132(15)$ \\
\hline Diastolic (mm Hg) & $74(10)$ & $75(10)$ & $73(9)$ & $71(8)$ \\
\hline \multicolumn{5}{|c|}{ Lung function (best of three readings at study entry assessment) and blood results } \\
\hline No of participants with data & 143 & 135 & 78 & 223 \\
\hline $\mathrm{PEF}(\mathrm{l} / \mathrm{min})$ & $380(126)$ & $388(125)$ & $365(105)$ & $345(114)$ \\
\hline $\mathrm{FEV}_{\mathrm{l}}(\mathrm{l})$ & $2.36(0.69)$ & $2.42(0.72)$ & $2.40(0.71)$ & $2.24(0.65)$ \\
\hline
\end{tabular}

$\mathrm{FEV}_{1}(\mathrm{l})$

$2.36(0.69)$

$2.42(0.72)$

$2.40(0.71)$

$2.24(0.65)$ 


\begin{tabular}{|c|c|c|c|c|}
\hline & \multicolumn{2}{|c|}{ Randomised trial } & \multicolumn{2}{|c|}{ Preference study } \\
\hline & Oral & Topical & Oral & Topical \\
\hline $\mathrm{Hb}(\mathrm{g} / \mathrm{l})$ & $141(11)$ & $141(11)$ & $139(10)$ & 139 (13) \\
\hline Creatinine $(\mu \mathrm{mol} / \mathrm{l})$ & $86(15)$ & $88(16)$ & 88 (17) & $88(15)$ \\
\hline Ferritin $(\mu \mathrm{g} / \mathrm{l})$ & $120(94)$ & $127(106)$ & $117(92)$ & $106(92)$ \\
\hline $\log _{\mathrm{e}}($ ferritin $(\mu \mathrm{g} / \mathrm{l})$ & $4.5(0.8)$ & $4.5(0.8)$ & $4.5(0.8)$ & $4.4(0.8)$ \\
\hline
\end{tabular}

$\mathrm{BMI}=$ body mass index; $\mathrm{IQR}=$ interquartile range, $\mathrm{PEF}=$ peak expiratory flow, $\mathrm{FEV}_{1}=$ forced expiratory volume in one second.

${ }^{*}$ Managers and senior officials, professionals, and associate professional and technical, better of self or partner. ${ }^{30}$

$\dagger 0=$ no symptoms, $100=$ maximum symptoms.

$\ddagger$ One person included in error with pain > half the days.

$\$ 95 \% \mathrm{Cl}$ for difference $-1 \%$ to $-21 \%$.

TExcluding seven participants with higher than eligible mean BP recorded.

in proportions, and rates with $95 \%$ confidence intervals with corrections for small numbers. STATA 9 was used for all the analyses (StataCorp, College Station, TX).

It is usual in equivalence studies to carry out an ontreatment analysis. As this study was testing two approaches to managing knee pain, however, we used an intention to treat approach for all our analyses.

For the 12 month analyses we used the data collected between 6 and 18 months that were closest to 12 months. For the 24 month analyses, we used data collected between 18 months and end of study closest to 24 months. Additionally, we carried out an end of study analysis using the last follow-up data collected on each participant, including end of study questionnaire data on some participants that was collected between 12 and 18 months and subsequent to their 12 month assessment.

\section{RESULTS}

\section{Participant recruitment}

We recruited 25 practices plus two pilot practices. There were no changes in protocol between the pilot

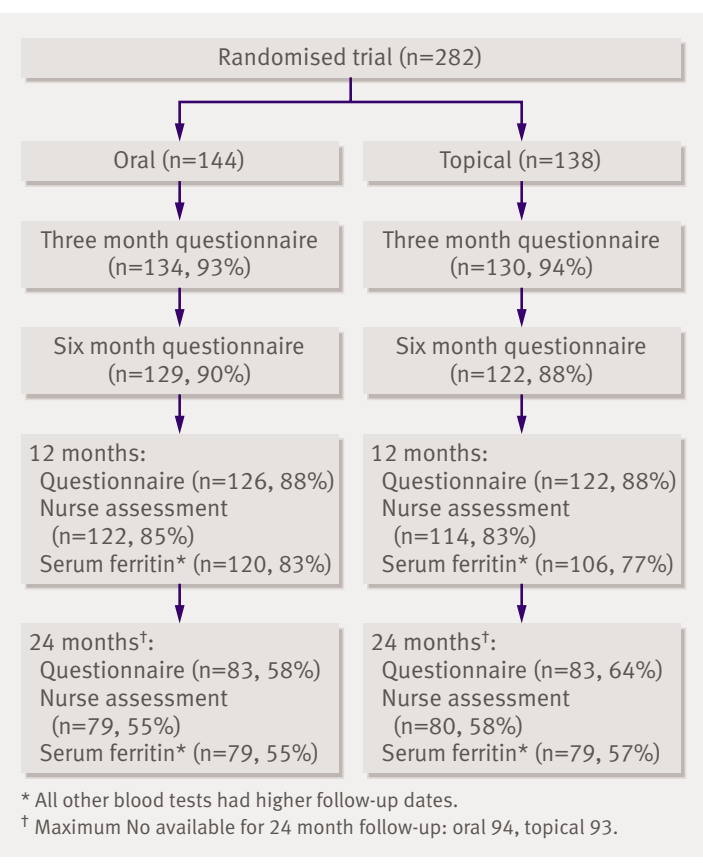

Fig 2 Participant follow-up in randomised trial and main studies so the pilot data contributed to our analyses. We excluded data from one pilot practice in which participants had also taken part in a nested qualitative study. ${ }^{22}$ The 26 practices had a registered population of 233558 with mean list size of 8983 (range 2922-16 100); their geographic distribution was broadly representative of the UK.

Recruitment took place from April 2003 to May 2005. The follow-up finished in May 2006. We approached $22870(89 \%)$ of the 26866 potential participants identified. We assessed 2859 of these who seemed eligible: 913 (32\%) did not meet the entry criteria for knee pain; 230 of the remaining 1946 (12\%) did not meet the consultation criteria; $25 / 1716$ had had a knee replacement; 609/1691 (36\%) failed the clinical history safety criteria; $10 / 1075(1 \%)$ failed other entry criteria; $86 / 1065,8 \%$ of the remainder, failed the safety criteria for hypertension. Finally two participants were excluded because of poor understanding of English. Of those eligible and interested at the end of the first assessment, 585/745 (79\%) eventually joined the study; 282 joined the randomised trial and 303 the preference study (fig 1).

Ten participants were entered into the study in error: one had dyspepsia; two had failed the consultation criteria; and seven had a mean recorded blood pressure at the study entry assessment that was slightly higher than allowed and missing repeat blood pressure record before study entry. They are included in the analyses, except that we did not use follow-up blood pressure data in those who failed the safety criteria for hypertension. Another participant who had a knee replacement was initially entered into the study but later removed.

\section{Baseline characteristics}

Participants' mean age was 64 years (SD 8.5) and median 64 years (range 50-89). Participants in the topical group in the preference study, but not those in the oral group, were older and of lower social class than those in the controlled trial. The remainder of participants' main baseline characteristics were broadly similar across all four groups. In particular, there were no differences between the two randomised groups except for some differences in their use of topical and oral NSAIDs in the previous year. In the preference study $89 \%$ of the oral group had used oral 
NSAIDs and $28 \%$ had used topical NSAIDs in the previous year, while in the topical group the rates of use of oral and topical drugs were $56 \%$ and $35 \%$, respectively. In the randomised trial, the attitude to topical treatment was less favourable in the topical group. Participants in the preference study generally expected their chosen medication to be effective or very effective. More participants in the preference study who chose to use oral NSAIDs had at least moderately troublesome pain in one or more additional body area (difference topical minus oral 11\% $(95 \%$ confidence interval $-21 \%$ to $-1 \%)$ (table 1$)$.

\section{Follow-up}

We obtained at least an $83 \%$ response to follow-up questionnaires, nurse assessment, and blood test data at 12 months. We obtained at least $55 \%$ of these data at 24 months ( $82 \%$ of those eligible for a 24 month followup) (figs 2 and 3 ).

\section{Primary outcome}

WOMAC scores changed little between baseline and the 12 month follow-up. For the global scores these were -0.5 (SD 17) in the oral group and 1.1 (SD 17) in the topical group in the randomised trial and 0.1 (SD 18) and 1.1 (SD17), respectively, in the preference study. Only for pain at 24 months in the randomised trial did the limits of the confidence intervals for the difference between oral and topical groups exceed our predefined limits for equivalence. We found no significant differences in the WOMAC global score changes between topical and oral groups in either study. For the WOMAC pain scores in the randomised trial 24 month and end of study analyses, there was a difference of borderline significance in favour of oral medication (table 2).

\section{Adverse effects}

We found no differences in major adverse effects. There were two deaths before the end of follow-up, both in the topical group in the preference study. One participant in the oral group in the preference study had an upper gastrointestinal haemorrhage during a planned admission to hospital.

The only difference in defined minor adverse effects was that fewer participants in the topical group in the randomised trial had a respiratory adverse effect $-9 \%$ $(-17 \%$ to $-2 \%)$. This was primarily explained by the higher proportion in the oral group whose peak expiratory flow dropped by $15 \%$ or more $(22(18 \%) v$ $9(8 \%))$. There were no differences in the proportions of participants having one or more defined adverse effects. The only significant mean difference in our clinical and laboratory measurements was in the randomised trial, where the change in creatinine concentrations at 12 months in the topical group was more favourable by $3.7 \mu \mathrm{mol} / \mathrm{l}(0.9 \mu \mathrm{mol} / 1$ to $6.5 \mu \mathrm{mol} /$ l) (table 3).

\section{Secondary outcomes}

We found no significant differences in the overall proportion with chronic pain grade III or IV at any time point or in the SF-36 physical component scores. In the preference study there was a difference of borderline significance in the SF-36 mental component score at three months that favoured oral treatment.

There were some differences in the disability component of the chronic pain grade at three months and in the end of study analyses in the randomised trial. Those in the oral group had slightly less pain related disability at three months and in the end of study analysis but not at 12 months. After we corrected for baseline differences there was a difference in the odds of having chronic pain grade III or IV at three months and in the end of study assessment, but not at 12 months, favouring the oral group (table 4).

\section{Adherence with treatment route}

There were no significant differences in the proportions in either study who reported in the 12 month questionnaire that they had changed treatment. In the randomised trial this apparent similarity masks

Table2 | Mean difference(95\% Cl for difference) in change in WOMAC ${ }^{\star}$ from baseline, for topical minus oral treatment with NSAIDs for knee pain in elderly people (adjusted by regression for baseline values)

\begin{tabular}{|c|c|c|c|c|c|}
\hline & 3 months & 6 months & 12 months & 24 months & End of study $†$ \\
\hline \multicolumn{6}{|l|}{ Randomised trial } \\
\hline No in oral/topical group $\ddagger$ & $133 / 129$ & $128 / 121$ & $125 / 121$ & $80 / 87$ & $139 / 132$ \\
\hline Pain & $-2(-6$ to 2$)$ & $1(-3$ to 5$)$ & $1(-4$ to 6$)$ & $6(0$ to 12$)$ & $5(0$ to 9$)$ \\
\hline Stiffness & $-3(-8$ to 2$)$ & $-4(-9$ to 1$)$ & $0(-6$ to 5$)$ & $-1(-8$ to 6$)$ & $-2(-7$ to 4$)$ \\
\hline Difficulty & $-2(-5$ to 2$)$ & $1(-3$ to 5$)$ & $3(-2$ to 7$)$ & $5(-1$ to 10$)$ & $3(-2$ to 7$)$ \\
\hline Global & $-2(-5$ to 2$)$ & $0(-3$ to 4$)$ & $2(-2$ to 6$)$ & $4(-1$ to 10$)$ & $3(-1$ to 7$)$ \\
\hline \multicolumn{6}{|l|}{ Preference study } \\
\hline No in oral/topical group $\ddagger$ & $71 / 198$ & $66 / 194$ & $70 / 184$ & $65 / 162$ & $75 / 209$ \\
\hline Pain & $-2(-7$ to 3$)$ & $-2(-7$ to 3$)$ & $-1(-7$ to 4$)$ & $0(-6$ to 6$)$ & $-1(-7$ to 5$)$ \\
\hline Stiffness & $0(-6$ to 6$)$ & $-3(-9$ to 3$)$ & $-2(-8$ to 4$)$ & $-2(-9$ to 5$)$ & $-3(-9$ to 3$)$ \\
\hline Difficulty & $2(-3$ to 6$)$ & $3(-2$ to 7$)$ & $2(-3$ to 7$)$ & $1(-5$ to 7$)$ & $1(-4$ to 6$)$ \\
\hline Global & $1(-3$ to 5$)$ & $1(-3$ to 5$)$ & $1(-4$ to 6$)$ & $0(-6$ to 6$)$ & $0(-5$ to 5$)$ \\
\hline
\end{tabular}

*Each WOMAC score has potential range of $0-100 ; 0=$ no symptoms, $100=$ maximum symptoms. Positive differences favour oral treatment.

$\dagger$ End of study value is last value carried forward or 24 month follow-up.

$\ddagger$ No of analysable WOMAC questionnaires. 
important differences: 11\% (95\% confidence interval $2 \%$ to $20 \%$ ) more of the topical group reported changing treatment because of inadequate pain relief and $10 \%(5 \%$ to $16 \%)$ more of the oral group reported changing treatment because of adverse effects. This was not seen in the preference study (table 5).

Over $80 \%$ of participants received prescriptions for their chosen or allocated treatment (table 6).

Only $5 \%$ of those randomised to the oral group, and nobody who chose oral treatment, had any prescriptions for topical NSAIDs. More of the topical group had prescriptions for oral NSAIDs (37\% in the randomised trial and $26 \%$ in the preference study). The average number of days' worth of oral NSAIDs prescribed in the randomised study was 139 and 61, respectively, in the oral and topical groups. In the preference study these were 159 and 28, respectively. We found no significant differences in the number of days' worth of "rescue medication" or drugs for adverse effects prescribed in either study. In the preference study, however, more of the oral group were prescribed "rescue medication"; this difference approaches significance $(-14 \%,-26 \%$ to $0.4 \%$ ) (table 6$)$.

\section{DISCUSSION}

\section{Main findings}

We found that advising patients to use either oral or topical NSAIDs produced equivalent clinical outcomes for knee pain over one year in both studies. Only for the pain subscale in the randomised trial at 24 months did limits of the confidence interval breech our definition of equivalence; this may be because of small numbers. There were no differences in the secondary patient centred outcomes except for suggestions, in the randomised trial, that those in the topical group were more likely to have more severe overall pain and disability as measured by the chronic pain grade at three months and in the end of study analysis adjusted for the baseline values, and that more people in the topical group stopped treatment because it was ineffective.

Although we found no differences in the overall numbers having major or defined minor adverse effects in either study, in the randomised trial we found an excess of respiratory adverse effects and a less favourable change in creatinine concentration in the oral group. These may be chance findings caused by multiple comparisons or they may represent real differences. The size of these differences could be clinically important; 9\% more in the oral group had an adverse respiratory effect that could justify stopping NSAIDs. At a population level, a difference in creatinine of $3.7 \mu \mathrm{mol} / 1$ might have important health consequences. ${ }^{23}$ Participants' reports in the randomised study showed that $11 \%$ of those in the oral group stopped taking NSAIDs because of adverse effects. Our data suggest that in the randomised trial oral NSAIDs caused more adverse effects. These differences were not seen in the preference study, even though the differences in daily doses of oral NSAIDs

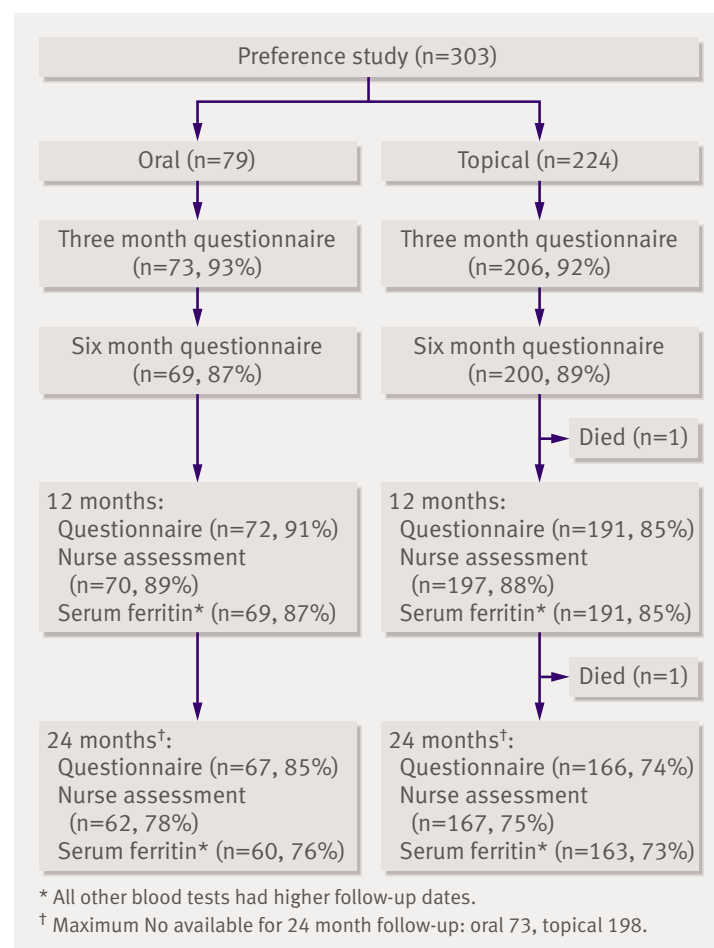

Fig 3 Participant follow-up in preference study

prescribed between the oral and topical groups were much greater than in the randomised trial. Possibly participants who chose oral treatment did so because of previous experience and so were more likely to tolerate adverse effects.

\section{Preferences}

Participants who wanted a choice predominantly selected topical rather than oral treatment, although those with more severe or widespread pain chose oral rather than topical treatment. Those who chose topical treatment tended to be older and of lower social class than those in the other three groups. There are likely to be other unmeasured differences between those in the preference study and the controlled trial, if only in the strength of their preferences for different treatments.

Those who chose oral NSAIDs seemed to be more tolerant of their adverse effects than those randomly allocated to the oral group, even though the oral group in the preference study took substantially more oral NSAIDs. In the nested qualitative study more widespread or chronic pain was perceived to be "more serious" and to require oral rather than topical medication. ${ }^{22}$ Thus participants in our preference study seemed to be making logical choices as to which administration route to use; this should perhaps be expected given that most of the participants had experienced knee pain for some time.

\section{Applicability to routine practice}

Our results are highly relevant to the management of knee pain in primary care. All our participants were receiving care from their general practitioner for knee 
Table 3 | Adverse effects* in elderly patients with knee pain according to NSAID treatment

$$
\text { Oral }
$$

Topical

Difference (topical-oral) $(95 \% \mathrm{Cl})$

Total (rate per 100 per year) with first unplanned hospital admission†

Randomised trial:

\begin{tabular}{|c|c|c|c|}
\hline $0-12$ months & $2(1.4)$ & $6(4.5)$ & $3.1(-1.0$ to 7.2$)$ \\
\hline $0-24$ months & $6(2.6)$ & $10(4.6)$ & $2.0(-1.5$ to 5.5$)$ \\
\hline \multicolumn{4}{|l|}{ Preference study: } \\
\hline $0-12$ months & $4(5.2)$ & $11(5.1)$ & $-0.1(-6.1$ to 5.8$)$ \\
\hline $0-24$ months & $6(4.3)$ & $19(4.9)$ & $0.6(-3.5$ to 4.7$)$ \\
\hline
\end{tabular}

No (\%) with defined minor adverse effects before 1 year

Randomised trial:

\begin{tabular}{|c|c|c|c|}
\hline No with data & 144 & 138 & - \\
\hline Gastrointestinal & $57(40)$ & $58(42)$ & $2 \%(-9 \%$ to $14 \%)$ \\
\hline Renovascular & $22(15)$ & $22(16)$ & $1 \%(-8 \%$ to $9 \%)$ \\
\hline Respiratory & $24(17)$ & $10(7)$ & $-9 \%(-17 \%$ to $-2 \%)$ \\
\hline Any minor adverse effect & $80(56)$ & $77(56)$ & $0(-11 \%$ to $12 \%)$ \\
\hline \multicolumn{4}{|l|}{ Preference study: } \\
\hline No with data & 79 & 224 & - \\
\hline Gastrointestinal & $29(38)$ & $82(37)$ & $-1 \%(-13 \%$ to $12 \%)$ \\
\hline Renovascular & 15 (19) & 34 (15) & $-4 \%(-14 \%$ to $6 \%)$ \\
\hline Respiratory & $14(18)$ & 34 (15) & $-3 \%(-13 \%$ to $7 \%)$ \\
\hline Any minor adverse effect & $45(57)$ & $118(53)$ & $-4 \%(-17 \%$ to $8 \%)$ \\
\hline \multicolumn{4}{|c|}{ Other measures of potential adverse effects; changes are one year minus baseline $\neq$} \\
\hline \multicolumn{4}{|l|}{ Randomised trial: } \\
\hline Change in haemoglobin $(\mathrm{g} / \mathrm{l})$ & $0.2(6.6)$ & $0.7(7.7)$ & $0.5(-1.3$ to 2.3$)$ \\
\hline Change in $\log _{\mathrm{e}}($ ferritin $\mu \mathrm{g} / \mathrm{l}$ ) & $-0.04(0.50)$ & $0.50(0.59)$ & $0.08(-0.07$ to 0.0 .22$)$ \\
\hline Change in systolic blood pressure $(\mathrm{mm} \mathrm{Hg})$ & $2.5(14)$ & $4.4(14)$ & $1.9(-1.7$ to 5.5$)$ \\
\hline Change in diastolic blood pressure $(\mathrm{mm} \mathrm{Hg})$ & $-1.0(8)$ & $-0.5(7)$ & $0.5(-1.3$ to 2.4$)$ \\
\hline Change in serum creatinine $(\mu \mathrm{mol} / \mathrm{l})$ & $2.4(11)$ & $-1.3(10)$ & $-3.7(-6.5$ to -0.9$)$ \\
\hline Change in PEF (l/min) & $-3(69)$ & $4(58)$ & $8(-9$ to 24$)$ \\
\hline No (\%) liver enzyme $\geq$ upper limit of normal ${ }^{30}$ & $3(2.2)$ & $3(2.7)$ & $0.4 \%(-3.4 \%$ to $4.3 \%)$ \\
\hline \multicolumn{4}{|l|}{ Preference study: } \\
\hline Change in haemoglobin $(\mathrm{g} / \mathrm{l})$ & $0.06(6.3)$ & $0.02(7.9)$ & $-0.04(-2.1$ to 2.0$)$ \\
\hline Change in $\log _{\mathrm{e}}($ ferritin $\mu \mathrm{g} / \mathrm{l}$ ) & $0.03(0.37)$ & $0.09(0.47)$ & $-0.07(-0.06$ to 0.19$)$ \\
\hline Change in systolic blood pressure $(\mathrm{mm} \mathrm{Hg})$ & $1.3(14)$ & $1.4(14)$ & $0.2(-3.8$ to 4.2$)$ \\
\hline Change in diastolic blood pressure $(\mathrm{mm} \mathrm{Hg})$ & $0.6(8)$ & $0.3(8)$ & $-0.3(-2.4$ to 1.8$)$ \\
\hline Change in serum creatinine $(\mu \mathrm{mol} / \mathrm{l})$ & $0.3(11)$ & $-1.7(11)$ & $-1.9(-4.8$ to 1.0$)$ \\
\hline Change in PEF (l/min) & $-4(68)$ & $-1(63)$ & $3(-15$ to 20$)$ \\
\hline No (\%) liver enzyme $\geq$ upper limit of normal ${ }^{30}$ & $2(3)$ & $2(1)$ & $-1.7 \%(-5.7 \%$ to $2.2 \%)$ \\
\hline
\end{tabular}

* Participants were included in denominator for specific category of side effect provided there was at least one instrument from which adverse effect in that category could be identified. Denominators may be lower for individual outcomes.

†First unplanned admission in each person only. Subsequent admissions are not counted.

fBlood result, either study or practice initiated, closest to one year and taken between six and 18 months. Mean time to follow-up blood test 1.

04 years (SD 0.10).

pain, and their general practitioner would still have considered prescribing NSAIDs if the study were not taking place. Further, as the choice of treatment in routine practice is not random but is affected by preferences of the clinician and patient, the preference study arm increases the relevance of our findings to routine practice.

Our participants had substantial problems with their knee pain, with nearly a third reporting that it was very or extremely troublesome. The mean WOMAC function/difficulty scores for each group were in the range 38-41 compared with the score of 31 suggested as the limit of symptoms acceptable to patients. ${ }^{24}$ They may differ from typical patients presenting in general practice in two important and related areas. Firstly, although we had no upper age limit for recruitment there was a preponderance of participants from younger age groups, so our results may not be directly applicable to the very elderly. Secondly, although most participants were identified because they had used NSAIDs, nearly half $(763 / 1691,45 \%)$ of those we assessed were deemed ineligible because they failed our safety criteria. The selection procedure may have produced a study population with a comparatively low risk of adverse effects related to NSAID use. Our results may not therefore be directly applicable to those who have most to gain from avoiding the toxicity of oral NSAIDs. The counterargument is that in very 
Table 4 | Secondary outcome measures in elderly patients with knee pain

3 months

6 months

12 months

24 months

End of study*

Mean difference in SF-36 (topical-oral) in change from baseline $†$ ( $95 \% \mathrm{Cl}$ for difference)

Randomised trial:

\begin{tabular}{|c|c|c|c|c|c|}
\hline No with data (topical/oral) & $123 / 122$ & $118 / 116$ & $115 / 119$ & $72 / 85$ & $127 / 129$ \\
\hline Physical component score & $-0.1(-1.7$ to 1.8$)$ & $-0.4(-2.0$ to 1.3$)$ & $-1.6(-3.5$ to 0.3$)$ & $-0.7(-3.0$ to 1.5$)$ & $-0.7(-2.5$ to 1.2$)$ \\
\hline Mental component score & $-1.2(-3.3$ to 0.9$)$ & $-1.7(-3.9$ to 0.4$)$ & $-1.0(-3.4$ to 1.3$)$ & $-0.4(-2.8$ to 2.1$)$ & $-0.5(-2.6$ to 1.7$)$ \\
\hline \multicolumn{6}{|l|}{ Preference study: } \\
\hline No with data (topical/oral) & $69 / 179$ & $62 / 177$ & $63 / 169$ & $60 / 143$ & $70 / 189$ \\
\hline Physical component score & $0.5(-1.2$ to 2.1$)$ & $0.8(-1.2$ to 2.7$)$ & $0.0(-2.0$ to 1.9$)$ & $-0.6(-2.8$ to 1.6$)$ & $0.4(-1.6$ to 2.3$)$ \\
\hline Mental component score & $-2.4(-4.8$ to -0.1$)$ & $-0.5(-2.9$ to 1.9$)$ & $-0.3(-2.7$ to 2.0$)$ & $-1.8(-4.4$ to 0.9$)$ & $-1.1(-3.5$ to 1.3$)$ \\
\hline \multicolumn{6}{|c|}{ Mean difference in change in chronic pain grade (topical minus oral) from baseline ( $95 \% \mathrm{Cl}$ of mean difference in change) } \\
\hline \multicolumn{6}{|l|}{ Randomised trial: } \\
\hline No with data (topical/oral) & $131 / 128$ & $124 / 119$ & $122 / 121$ & $79 / 87$ & $137 / 131$ \\
\hline Pain intensity & $0.1(-3.8$ to 4.1$)$ & $1.1(-3.1$ to 5.3$)$ & $2.1(-2.7$ to 7.0$)$ & $0.4(-6.1$ to 6.8$)$ & $2.8(-2.2$ to 7.8$)$ \\
\hline Disability & $4.9(0.2$ to 9.6$)$ & $4.4(-0.9$ to 9.7$)$ & $4.7(-1.2$ to 10.7$)$ & $3.6(-3.3$ to 10.5$)$ & $6.5(0.9$ to 12.4$)$ \\
\hline Odds ratio for high $\mathrm{CPG} \dagger$ & 2.3 (1.1 to 4.5$)$ & $1.3(0.7$ to 2.5$)$ & $1.3(0.7$ to 2.5$)$ & 2.1 (1.0 to 4.5$)$ & 2.0 (1.1 to 3.7$)$ \\
\hline \multicolumn{6}{|l|}{ Preference study: } \\
\hline No with data (topical/oral) & $73 / 201$ & $69 / 195$ & $70 / 189$ & $67 / 161$ & $76 / 208$ \\
\hline Pain intensity & $1.2(-3.0$ to 5.4$)$ & $2.5(-2.6$ to 7.6$)$ & $4.3(-0.6$ to 9.1$)$ & $2.0(-3.9$ to 7.8$)$ & $0.4(-4.9$ to 5.7$)$ \\
\hline Disability & $3.8(-1.4$ to 8.9$)$ & $0.7(-5.1$ to 6.4$)$ & $1.4(-4.6$ to 7.4$)$ & $6.5(-0.6$ to 13.5$)$ & $5.2(-1.0$ to 11.3$)$ \\
\hline Odds ratio for high CPG & 1.5 (0.71 to 3.2$)$ & 0.8 (0.39 to 1.6$)$ & $1.1(0.5$ to 2.1$)$ & $1.7(0.8$ to 3.4$)$ & $1.4(0.7$ to 2.7$)$ \\
\hline
\end{tabular}

$\mathrm{CPG}=$ chronic pain grade.

*End of study value is last value carried forward or 24 month follow-up.

†Lower scores on SF-36 indicate worse health state, negative values favour oral treatment.

$\ddagger$ Topical $v$ oral, adjusted for baseline. Odds ratio $>1.0$ favours oral treatment.

elderly people and those who would fail our safety criteria the risks of using oral NSAIDs are always too great.

Setting these concerns about generalisability to routine practice into context, our participants' physical health as measured by the SF-36 physical component score for each group in our study was in the range $37.7-$ 39.0. This compares with mean values of $32.0,{ }^{25} 35.9,{ }^{26}$ and $43.6^{27}$ found in observational studies of patients with osteoarthritis of the knee.

Participants' choices about joining the study may have been influenced by their past experience of
NSAID use so we mainly recruited people who were tolerant of related adverse effects. In the nested qualitative study, however, we found that participants had different ideas from general practitioners about what these adverse effects were. ${ }^{22}$ Indeed some participants were willing to endure a great deal of discomfort before alerting their general practitioner to their problems. As well as our findings on minor adverse effects, the well known risks of serious related adverse effects need to be included in any consideration of the comparative risk of oral and topical treatment.

Table 5 Changes reported by patients between treatments over 12 months*. Denominator for (percentages) is all participants

\begin{tabular}{|c|c|c|c|}
\hline & Oral & Topical & Difference (topical minus oral) \\
\hline \multicolumn{4}{|l|}{ Randomised trial } \\
\hline No with data & 144 & 138 & \\
\hline $\begin{array}{l}\text { Taking other mode of NSAID for more days in previous } \\
\text { month }\end{array}$ & $7(5)$ & $22(16)$ & $11 \%$ (4\% to $18 \%)$ \\
\hline Patient reported change in treatment & $41(28)$ & $44(32)$ & $4 \%(-6 \%$ to $15 \%)$ \\
\hline Changed because of inadequate pain relief & $18(13)$ & $32(23)$ & $11 \%(2 \%$ to $20 \%)$ \\
\hline Changed because of any adverse effects & $16(11)$ & $1(1)$ & $-10 \%(-16 \%$ to $-5 \%)$ \\
\hline Changed for other reasons & $9(6)$ & $11(8)$ & $-2 \%(-8 \%$ to $4 \%)$ \\
\hline \multicolumn{4}{|l|}{ Preference study } \\
\hline No with data & 79 & 224 & \\
\hline $\begin{array}{l}\text { Taking other mode of NSAID for more days in previous } \\
\text { month }\end{array}$ & $1(1)$ & $23(10)$ & $9 \%(4 \%$ to $14 \%)$ \\
\hline Patient reported change in treatment & $23(29)$ & $45(20)$ & $-9 \%(-20 \%$ to $2 \%)$ \\
\hline Changed because inadequate pain relief & $10(13)$ & $22(10)$ & $-3 \%(-11 \%$ to $5 \%)$ \\
\hline Changed because of any adverse effects & $7(9)$ & $8(4)$ & $-5 \%(-12 \%$ to $1.4 \%)$ \\
\hline Changed for other reasons & $6(8)$ & $16(7)$ & $-0.5 \%(-7 \%$ to $6 \%)$ \\
\hline
\end{tabular}

*Data come from 3, 6, and 12 month questionnaires. Only first recorded change used. 
Table 6 | All drugs prescribed over 12 months of follow-up

\begin{tabular}{|c|c|c|c|c|c|c|}
\hline & \multicolumn{3}{|c|}{ No (\%) prescribed drug } & \multicolumn{3}{|c|}{ Mean (SD) daily doses prescribed per participant* } \\
\hline & Oral & Topical & $95 \% \mathrm{Cl} \dagger$ & Oral & Topical & $95 \% \mathrm{Cl} \dagger$ \\
\hline \multicolumn{7}{|l|}{ Randomised trial } \\
\hline No with data & 130 & 124 & - & 130 & 124 & - \\
\hline All oral NSAIDs & $119(92)$ & $46(37)$ & $-64 \%$ to $-45 \%$ & $139(116)$ & $61(126)$ & -109 to -49 \\
\hline All topical NSAIDs & $6(5)$ & $103(83)$ & $71 \%$ to $86 \%$ & $7(40)$ & 211 (249) & 161 to 248 \\
\hline "Rescue medication" $\ddagger$ & $55(42)$ & $57(46)$ & $-9 \%$ to $16 \%$ & $43(107)$ & $34(67)$ & -31 to 13 \\
\hline Cardiovascular drugs & $58(45)$ & $46(37)$ & $-20 \%$ to $5 \%$ & 265 (448) & $181(355)$ & -183 to 17 \\
\hline Indigestion drugs & $21(16)$ & $27(22)$ & $-4 \%$ to $15 \%$ & $26(81)$ & $27(78)$ & -19 to 20 \\
\hline Respiratory drugs & $5(4)$ & $8(6)$ & $-3 \%$ to $8 \%$ & $19(132)$ & $16(87)$ & -31 to 25 \\
\hline \multicolumn{7}{|l|}{ Preference study } \\
\hline No with data & 76 & 210 & - & 76 & 210 & - \\
\hline All oral NSAIDs & $67(88)$ & $55(26)$ & $-71 \%$ to $-53 \%$ & 159 (132) & $28(73)$ & -155 to -107 \\
\hline All topical NSAIDs & $0(0)$ & $170(81)$ & $76 \%$ to $86 \%$ & $0(0)$ & 245 (279) & 182 to 308 \\
\hline "Rescue medication" $\ddagger$ & $40(53)$ & $84(40)$ & $-26 \%$ to $0.4 \%$ & $49(89)$ & $40(76)$ & -31 to 11 \\
\hline Cardiovascular drugs & $32(42)$ & $79(38)$ & $-17 \%$ to $8 \%$ & $246(497)$ & $256(481)$ & -118 to 138 \\
\hline Indigestion drugs & $10(13)$ & $32(15)$ & $-7 \%$ to $11 \%$ & $18(74)$ & $16(51)$ & -17 to 14 \\
\hline Respiratory drugs & $7(9)$ & $33(16)$ & $-2 \%$ to $15 \%$ & $75(483)$ & $43(157)$ & -107 to 42 \\
\hline
\end{tabular}

*Denominator is all participants.

†For difference.

$\ddagger$ Total defined daily doses of paracetamol and opioid analgesics.

\section{Statistical power}

Good recruitment and follow-up rates, and the fact that the final imbalance between oral and topical in the preference study was less than anticipated, means that we had ample power for our primary effectiveness analyses at 12 months. The conclusions for 24 months, however, are weaker, particularly in the randomised trial, because of the smaller numbers available for follow-up.

\section{Potential for bias}

We did not attempt to blind the participants or practices. This was deliberate as we wanted to compare two forms of usual treatment, but it might have introduced bias in the questionnaires as these mostly asked participants for subjective judgments. The measurements taken by the research nurses and the data from medical records should be less prone to bias.

\section{Use of prescribed medication}

The amount of NSAID consumed in this trial was lower than in many controlled trials; most trials of NSAIDs use high dose regimens and expect good adherence to

\section{WHAT IS ALREADY KNOWN ON THIS TOPIC}

Oral and topical non-steroidal anti-inflammatory drugs (NSAIDs) have short term beneficial effects for people with osteoarthritis

Oral NSAIDs have a high incidence of adverse effects

\section{WHAT THIS STUDY ADDS}

Advice to use oral or topical NSAIDs has an equivalent effect on knee pain in the long term

Topical NSAIDs may be a useful alternative to oral NSAIDs treatment-for example, in the VIGOR/Vioxx gastrointestinal outcomes research) study $71 \%$ of participants continued medication during follow-up, $99 \%$ of whom took at least $75 \%$ of the doses intended. ${ }^{2829}$ Thus, the clinical effects and rates of adverse effects observed in some other trials may overestimate what happens when these drugs are used in routine practice. The pattern of drug use we observed is more likely to be representative of how NSAIDs are prescribed in routine practice. One caveat when interpreting these prescribing data is that we were not able to measure the use of topical or oral NSAIDs purchased over the counter, nor to estimate the proportion of prescribed medication the participants actually used.

\section{Meaning of the study}

What is clear is that the outcome for knee pain at one year is equivalent, whether patients are initially advised to use oral or topical treatment. This is a consistent finding in both the randomised trial and the preference study.

Though we carried out multiple comparisons at different time points, the only comparisons that indicated a difference in effectiveness were the change in chronic pain grade III/IV at three months and at the end of the study in the randomised trial, and the fact that more participants reported changing treatment because of inadequate pain relief, again in the randomised trial. Both changes favoured oral treatment. Those in the topical groups who had inadequate pain relief might subsequently have obtained adequate pain relief from other, probably oral, drugs.

We have compared advice to use one of two active preparations, neither of which is known to have long term efficacy. We cannot use these data to conclude that advice to use either preparation is superior to 
paracetamol, placebo, or no treatment. Indeed, the absence of clear change in WOMAC scores between baseline and follow-up, in both arms of either study, is consistent with several hypotheses including the notion that neither preparation is particularly effective. Advice to use topical NSAIDs might, however, be a useful alternative to advice to use oral NSAIDs for knee pain in older people.

We thank all the people who took part in the study and the following hospital laboratories for processing blood tests: Ashford and St Peter's Trust, Chertsey; Barnet and Chase Farm Hospitals NHS Trust, Barnet; Belfast City Hospital Trust, Belfast; County Durham and Darlington Acute Hospitals NHS Trust, Darlington; Fife Acute Hospitals NHS Trust, Kirkcaldy; James Paget University Hospitals NHS Foundation Trust, Gorleston; Kettering General Hospital NHS Trust, Kettering; Maidstone and Tunbridge Wells NHS Trust, Tunbridge Wells; Mater Hospital Trust, Belfast; North Cumbria Acute Hospitals NHS Trust; Pembrokeshire and Derwent N HS Trust, Haverfordwest; Peterborough and Stamford Hospital NHS Foundation Trust, Peterborough; Poole Hospital NHS Trust, Poole; Sherwood Forest Hospitals NHS Trust, Sutton-in-Ashfield; Shrewsbury and Telford Hospital NHS Trust, Shrewsbury; South Devon Healthcare N HS Trust, Torquay; South Tees Hospitals NHS Trust, Middlesbrough; Taunton and Somerset NHS Trust, Taunton; United Bristol Healthcare N HS Trust, Bristol; United Hospitals Health and Social Services Trust, Antrim; University Hospitals of Morecambe Bay NHS Trust, Kendal; Walsall Hospitals NHS Trust, Walsall; West Suffolk Hospital NHS Trust, Bury St Edmunds; Wirral Hospital NHS Trust, Upton; Worcestershire Acute Hospitals NHS Trust, Redditch; York Hospitals NHS Trust, York. We thank Lynette Edwards for comments on earlier drafts of this paper and Dawn Carnes for assistance in preparing this paper.

Other members of the study team were Valerie Brueton, Gene Feder,

Bruce Kidd, Hansa Shah, and Helen Tate.

General practice research framework

Regional nurses: Jane Elwood, Kay Foulger, Sue Fox, Anne Hall, Lesley Hand, Angela Hill, Fiona Leslie, Eileen Marshall, Anna Williams. Lead general practitioners: P G Austin, R Brownlie, V Buntwal, H Byrne, A Darrah, J Durkan, Christopher Hand, D P Houlahan, A Howitt, D Jones, M Leci, S H Rogerson, E Montague, N McGreevy, T McVey, C R Pierce,

ERule, A Sood, W H Smithson, G Stein, Amrit Takhar, PThrower, S Warlow, C J Watkins, A J S White, SM Williams, Michael Yardley.

Research nurses:G Bryant, J Byrne, M Clark, J Copland, M Cotterill, M Couche, J Elwood, S Fox, A Hall, S Hallam, L Hand, D Hanlon, A Hogg, A Houlahan, J Jackson, M Lloyd, J Madden, J McArdle, C McVey, F Morris, A Norton, K O'Brien, S Robinson, M Rogerson, J Simmonds, C Teward, A Thompson, G White, A Williams, G Wilkinson.

Randomisation team at MRC Clinical Trials Unit: Omobola Fadahunsi,

Rhian Gabe, Ann Gerrard, Farid Miah, Sinead Nally, Angela Poland. Trial steering committee: Marta Buszewicz, John Grimley-Evans (chair), Elaine Hay, Stephen Lemon, Paul Little, Ursula Shine.

Data monitoring and ethics committee: Ade Adebajo, Liam Smeeth (chair), Richard Morris

Contributors: MU was the principal investigator, was primarily responsible for the original grant application, and led the trial team. He contributed to analysing and interpreting the data, wrote the first draft, and is guarantor. DA was study statistician and contributed to the analysis plan and analyses. PC was the clinical research fellow and led on developing the study paperwork, assisted with management, and liaised with laboratories and general practices on medical matters. She wrote the MIQUEST searches and worked with the practice research nurses to identify participants. EH produced the analysis plan and statistical analyses and is guarantor for statistical aspects. LL was responsible for all nursing activity, contributed to implementation of design, selecting and recruiting participants, and developing trial documentation, and managed the recruitment of participating practices. JM was one of the original applicants and contributed to development of protocol and procedures and developed fieldwork costings and was responsible for quality control of the fieldwork. SMtI contributed to the statistical analysis plan and carried out statistical analyses. SP was one of the original applicants, was a member of the project board, and contributed to the study design and development of the protocol. MV was one of the original applicants, contributed to the original design and procedures and had overall responsibility for trial fieldwork and management. She was a member of the project board and the trial steering committee. KW was the study manager.

Funding: This study was commissioned by the NHS Health Technology Assessment Programme, project reference 01/09/02. Goldshield

Pharmaceuticals supplied the starter packs of topical ibuprofen. Competing interests: $\mathrm{MU}$ has received speaker fees from Pfizer, the manufacturers of celecoxib.

Ethical approval: Northern and Yorkshire multi-centre research ethics committee (MREC 2/3/1). The 28 local research ethics committees also gave approval.

Provenance and peer review: Not commissioned; externally peer reviewed.

1 Gabriel SE. Update on the epidemiology of the rheumatic diseases. Curr Opin Rheumatol 1996;8:96-100.

2 Thomas E, Peat G, Harris L, Wilkie R, Croft PR. The prevalence of pain and pain interference in a general population of older adults: crosssectional findings from the North Staffordshire Osteoarthritis Project (NorStOP). Pain 2004;110:361-8.

3 Urwin M, Symmons D, Allison T, Brammah T, Busby H, Roxby M, et al. Estimating the burden of musculoskeletal disorders in the community: the comparative prevalence of symptoms at different anatomical sites, and the relation to social deprivation. Ann Rheum Dis 1998;57:649-55.

4 O'Reilly SC, Muir KR, Doherty M. Screening for pain in knee osteoarthritis: which question? Ann Rheum Dis 1996;55:931-3.

5 Pendleton A, Arden N, Dougados M, Doherty M, Bannwarth B, Bijlsma JWJ, et al. EULAR recommendations for the management of knee osteoarthritis: report of a task force of the standing committee for international clinical studies including therapeutic trials (ESCISIT). Ann Rheum Dis 2000;59:936-44.

6 Towheed TE, Hochberg MC. A systematic review of randomized controlled trials of pharmacological therapy in osteoarthritis of the knee, with an emphasis on trial methodology. Semin Arthritis Rheum 1997; $26: 755-70$.

7 Mason L, Moore RA, Edwards JE, Derry S, McQuay HJ. Topical NSAIDs for chronic musculoskeletal pain: systematic review and metaanalysis. BMC Musculoskelet Disord 2004;5:28.

8 Lin J, Zhang W, Jones A, Doherty M. Efficacy of topical non-steroidal anti-inflammatory drugs in the treatment of osteoarthritis: metaanalysis of randomised controlled trials. BMJ 2004;329:324.

9 Towheed TE. Pennsaid therapy for osteoarthritis of the knee: a systematic review and meta-analysis of randomized controlled trials. J Rheumatol 2006;33:567-73.

10 Cross PL, Ashby D, Harding G, Hennessy EM, Letley L, Parsons S, et al. TOIB Study. Are topical or oral ibuprofen equally effective for the treatment of chronic knee pain presenting in primary care: a randomised controlled trial with patient preference study. $B M C$ Musculoskelet Disord 2005;6:55.

11 Medical Research Council. General practice research framework. www.gprf.mrc.ac.uk.

12 Jinks C, Lewis M, Ong BN, Croft P. A brief screening tool for knee pain in primary care. 1. Validity and reliability. Rheumatology (Oxford) 2001; 40:528-36.

13 Altman R, Asch E, Bloch D, Bole G, Borenstein D, Brandt K, et al. Development of criteria for the classification and reporting of osteoarthritis. Classification of osteoarthritis of the knee. Diagnostic and therapeutic criteria committee of the American Rheumatism Association. Arthritis Rheum 1986;29:1039-49.

14 Parsons S, Carnes D, Pincus T, Foster N, Breen A, Vogel S, et al. Measuring troublesomeness of chronic pain by location. $B M C$ Musculoskelet Disord 2006;7:34.

15 Bellamy N, Buchanan WW, Goldsmith CH, Campbell J, Stitt LW. Validation study of WOMAC: a health status instrument for measuring clinically important patient relevant outcomes to antirheumatic drug therapy in patients with osteoarthritis of the hip or knee. J Rheumatol 1988;15:1833-40.

16 Von Korff M, Ormel J, Keefe FI, Dworkin SF. Grading the severity of chronic pain. Pain 1992;50:133-49.

17 Smith BH, Penny KI, Purves AM, Munro C, Wilson B, Grimshaw J, et al. The chronic pain grade questionnaire: validation and reliability in postal research. Pain 1997;71:141-7.

18 Garratt AM, Ruta DA, Abdalla MI, Buckingham JK, Russell IT. The SF-36 health survey questionnaire: an outcome measure suitable for routine use within the NHS? BMJ 1993;306:1440-4.

19 Ware JE, Kosinski M, Dewey JE. How to score version 2 of the SF-36 (r) health survey . Lincoln, RI: Quality Metric, 2000.

20 Underwood MR, Carnes D, Cross P, Harding G, Hennessy E, Letley L, et al. Topical or oral ibuprofen for chronic knee pain in older people (TOIB). Health Technol Assess (in press).

21 WHO Collaborating Centre for Drug Statistics Methodology. ATC/DDD system . www.whocc.no/atcddd. 
22 Carnes D, Anwer Y, Harding G, Underwood M, Parsons S, on behalf of the TOIB study team. Influences on older people's decision making regarding choice of topical or oral NSAIDs for their knee pain: qualitative study. BMJ 2007 doi: 10.1136/bmj.39401.699063.BE.

23 Shlipak MG, Stehman-Breen C, Vittinghoff E, Lin F, Varosy PD, Wenger NK, et al. Creatinine levels and cardiovascular events in women with heart disease: do small changes matter? Am J Kidney Dis 2004; 43:37-44.

24 Tubach F, Ravaud P, Baron G, Falissard B, Logeart I, Bellamy N, et al. Evaluation of clinically relevant states in patient reported outcomes in knee and hip osteoarthritis: the patient acceptable symptom state. Ann Rheum Dis 2005;64:34-7.

25 Rannou F, Boutron I, Jardinaud-Lopez M, Meric G, Revel M, Fermanian J, et al. Should aggregate scores of the medical outcomes study 36-item short form health survey be used to assess quality of life in knee and hip osteoarthritis? A national survey in primary care. Osteoarthritis Cartilage 2007;15:1013-8.
26 Salaffi F, Carotti M, Grassi W. Health-related quality of life in patient with hip or knee osteoarthritis: comparison of generic and diseasespecific instruments. Clin Rheumatol 2005;24:29-37.

27 Fransen M, Edmonds J. Reliability and validity of the EuroQol in patients with osteoarthritis of the knee. Rheumatology (Oxford) 1999;38:807-13.

28 Kearney PM, Baigent C, Godwin J, Halls H, Emberson JR, Patrono C. Do selective cyclo-oxygenase- 2 inhibitors and traditional non-steroidal anti-inflammatory drugs increase the risk of atherothrombosis? Metaanalysis of randomised trials. BMJ 2006;332:1302-8.

29 Bombardier C, Laine L, Reicin A, Shapiro D, Burgos-Vargas R, Davis B, et al. Comparison of upper gastrointestinal toxicity of rofecoxib and naproxen in patients with rheumatoid arthritis. $N$ Engl J Med 2000;343:1520-8

30 Office for National Statistics. Standard occupational classification 2000. London: Stationery Office, 2007.

Accepted: 7 November 2007 